\title{
EDM of Reverse-Tapered Microholes Using Bent Electrodes
}

\author{
Kai EGASHIRA*, Aya MASUDA*, Hachiro TSUCHIYA* and Makoto MIYAZAKI* \\ (Received on March 30, 2007)
}

*Kyoto Institute of Technology, Matsugasaki, Sakyo Ward, Kyoto 606-8585, Japan

\begin{abstract}
Electrical discharge machining (EDM) of a tapered microhole from its smaller opening is more difficult to perform than from its larger opening. Such drilling, however, is unavoidable for some applications. EDM of reverse-tapered microholes has therefore been attempted using bent electrodes. The bent electrodes were fabricated from a stepped or notched straight electrode, which was bent at its step or notch. Using such electrodes, reverse-tapered shapes were obtained by controlling the electrode feed direction and rotation. As a result, holes with a diameter of less than $100 \mu \mathrm{m}$ and a cone angle of up to $90^{\circ}$ were successfully drilled in copper plates. The circularity of drilled holes and the machining time improved in comparison with those obtained in a previous study. Combinations of straight and tapered holes, and tapered and straight holes were also drilled. Furthermore, this technique was used to chamfer one opening of a hole from the opposite opening.
\end{abstract}

Key words: reverse-tapered hole, microhole, EDM, bent electrode, chamfering

\section{INTRODUCTION}

Electrical discharge machining (EDM) has been widely employed for drilling microholes in various materials, because it can deal with hard materials and the machining force exerted on a workpiece is much smaller than that in mechanical machining processes. The primary applications of such microholes are as nozzles for injecting fuel or forming fibers, and as dies for drawing wires. These holes often need to be tapered with one opening larger than the other. Although a tapered hole is usually drilled from its larger opening for ease of machining, such drilling is difficult to carry out in some cases, requiring a method of producing a reverse-tapered hole with an overhang.

As an EDM method for fabricating a shape with an overhang such as a reverse-tapered hole, Goto et al. have developed an EDM system with a flexible arm, on whose tip an electrode was fixed ${ }^{1)}$. Holes with a large overhang similar to mole tunnels were fabricated. This method, however, cannot be applied to microholes, because the arm has mechanical parts inside it and minimizing its size is limited. Although wire-EDM can produce a reverse-tapered hole using an inclined wire electrode, it also has difficulty in drilling a microhole owing to the wire diameter being close to the hole diameter.

Masuzawa et al. have successfully fabricated reverse-tapered microholes with various cone angles ${ }^{2 / 3)}$. However, their method requires a lathetype EDM machine and holes with a diameter of less than $100 \mu \mathrm{m}$ were not fabricated. Diver et al. have reported that drilling reverse-tapered microholes was possible using a conventional machine ${ }^{4}$. Holes with a high aspect ratio were drilled with an electrode bent by a guiding collet and then fed into a workpiece. However, the electrode cannot be bent at a large angle because it is elastically bent, making it difficult to drill holes with a large cone angle. Furthermore, they were also unable to fabricate holes with a diameter of less than $100 \mu \mathrm{m}$.

We have therefore drilled reverse-tapered holes of less than $100 \mu \mathrm{m}$ diameter using plastically bent electrodes $^{5)}$. As a result, a hole of $50 \mu \mathrm{m}$ entrance diameter and $115 \mu \mathrm{m}$ exit diameter was fabricated. However, its circularity was poor with approximate values of $4 \mu \mathrm{m}$ owing to uneven electrode wear and to the absence of continuous rotation of the electrode, because the electrode feed motion was controlled by adjusting the electrode rotation angle. Moreover, the machining time was long because this feed motion was manually controlled. In this study, we have therefore attempted to improve the hole circularity and machining time in the EDM of reverse-tapered microholes by modifying the electrode shape and feed motion. Drilling combinations of straight and reverse-tapered holes, and reverse-tapered and straight holes was also attempted. Furthermore, this technique was used to chamfer one opening of a hole from the opposite opening.

\section{EXPERIMENTAL}

\subsection{Experimental setup}

In the present study, electrode preparation and reverse-tapered microhole drilling were performed using a micro-EDM machine (MG-ED72, Matsushita Electric Industrial Co., Ltd.) and a microultrasonic machine (ASWU-1, Creative Technology Corp.), respectively. Figure 1 shows the schematic configuration of the main parts of the microultrasonic machine. Its three axes are driven at a step feed of $0.05 \mu \mathrm{m}$. The spindle system includes a V-shaped sliding bearing, a mandrel, and a DC motor, which are the same components as those used 


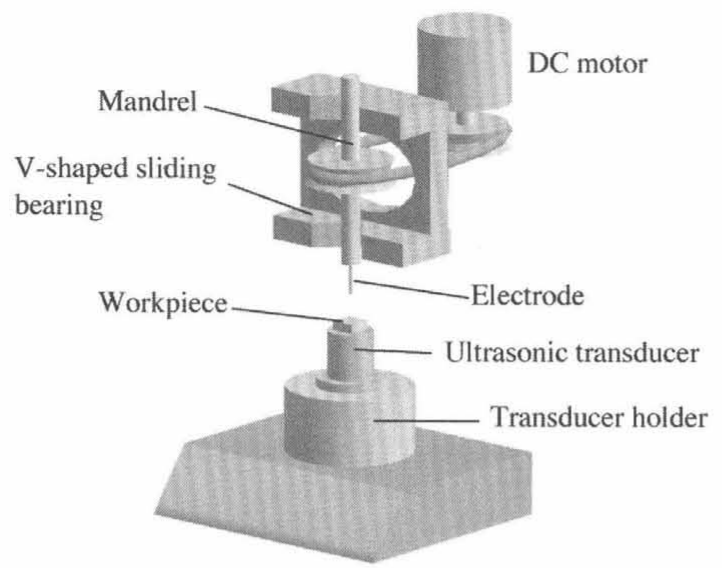

Fig. 1 Schematic configuration of main parts of microultrasonic machine

for the micro-EDM machine. The mandrel holds an electrode and rotates at a rotation speed of $3000 \mathrm{~min}^{-1}$. Its cylindricality is such that the rotation run-out is less than $0.5 \mu \mathrm{m}$.

The EDM conditions for reverse-tapered microholes are shown in Table 1. Drilling was performed in a $20 \mu \mathrm{m}$ - or $50 \mu \mathrm{m}$-thick copper plate using tungsten electrodes. The microultrasonic machine is provided with an RC-type electricaldischarge circuit for the on-the-machine fabrication of ultrasonic-machining tools by EDM. The present experiments utilized this circuit for drilling. The open-circuit voltage was set to 40-100V. Drilling was performed only with the stray capacitance of the machine, which was approximately $30 \mathrm{pF}$, because no capacitor was connected to the circuit. The electrode feed motion was controlled by monitoring the average charging current. The electrode was fed or retracted, with an average charging current smaller or larger than $1 \mathrm{~mA}$, respectively.

The workpiece was ultrasonically oscillated during the machining to prevent debris and bubbles from collecting at the discharge gap. It was attached to the tip of an ultrasonic transducer using adhesive tape and vertically oscillated. The oscillation frequency and amplitude were $40 \mathrm{kHz}$ and $0.4 \mu \mathrm{m}$, respectively.

\subsection{Experimental procedure}

Figure 2 illustrates the experimental procedure. A cylindrical electrode is fabricated by wire electrodischarge grinding $(\mathrm{WEDG})^{6)}$ on the micro-EDM
Table 1 EDM conditions for reverse-tapered microholes

\begin{tabular}{|c|c|}
\hline Electrical-discharge circuit & RC type \\
\hline Polarity & $\begin{array}{l}\text { Electrode }(-), \\
\text { Workpiece }(+)\end{array}$ \\
\hline Open-circuit voltage & $40-100 \mathrm{~V}$ \\
\hline Electrical capacitance & Stray capacitance \\
\hline Charging resistance & $1.1 \mathrm{k} \Omega$ \\
\hline Average charging current & $1 \mathrm{~mA}$ \\
\hline Electrode material & Tungsten \\
\hline Workpiece & $\begin{array}{l}\text { Copper plate }(20 \mu \mathrm{m} \\
\text { or } 50 \mu \mathrm{m} \text { thick) }\end{array}$ \\
\hline Electrode rotation speed & $3000 \mathrm{~min}^{-1}$ \\
\hline Working fluid & EDM oil \\
\hline Ultrasonic oscillation frequency & $40 \mathrm{kHz}$ \\
\hline Ultrasonic oscillation amplitude & $0.4 \mu \mathrm{m}$ \\
\hline
\end{tabular}

machine and is then bent using the edge of a glass plate (Fig. 2(a)). It is pushed against the plate until its bending angle reaches half the cone angle of a hole to be drilled. The bent electrode is mounted on the microultrasonic machine and drilling begins. The electrode is fed into the workpiece in the direction of its bent-part axis, thus drilling an inclined hole (Fig. 2(b)). $F_{1}$ indicates the vertical electrode feed length in this step. The electrode is then vertically fed until its straight part penetrates through the workpiece (Fig. 2(c)). $F_{2}$ indicates the electrode feed length in this step. In the next step, the electrode is rotated and fed vertically upward, fabricating a reverse-tapered shape (Fig. 2(d)). The electrode feed length in this step is indicated as $F_{3}$. After that, with the EDM power source being turned off, the rotation of the electrode is stopped and it is extracted from the workpiece in the direction of its bent-part axis (Fig. 2(e)). The machining in Figs. 2(b), (c), and (d) is carried out mainly at the tip, lower-side surface, and
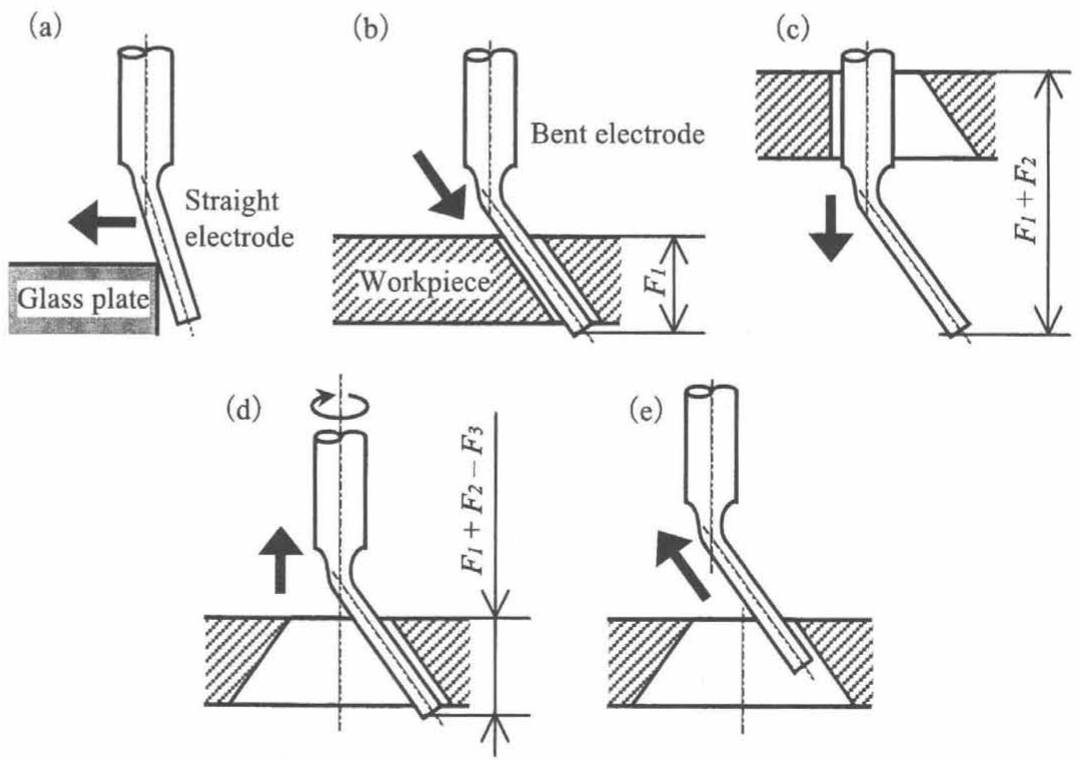

Fig. 2 Experimental procedure 


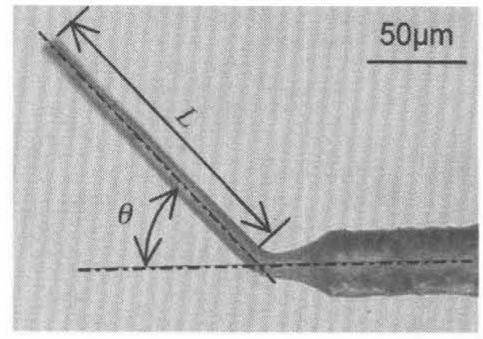

Fig. 3 Stepped electrode (bent-part diameter $=12 \mu \mathrm{m}$, straight-part diameter $=30 \mu \mathrm{m}, \theta=45^{\circ}$, and $L=$ $145 \mu \mathrm{m})$

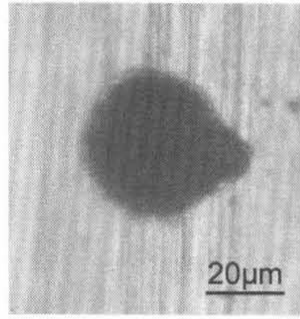

(a) Entrance

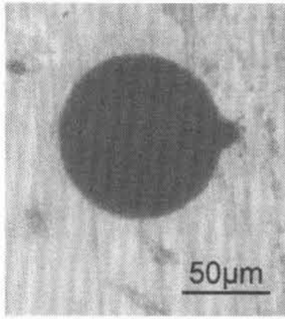

(b) Exit
Fig. 4 Reverse-tapered microhole $\left(\theta=30^{\circ}, L=110 \mu \mathrm{m}\right.$, $F_{1}=75 \mu \mathrm{m}, F_{2}=100 \mu \mathrm{m}$, and $\left.F_{3}=100 \mu \mathrm{m}\right)$

upper-side surface of the electrode, respectively, utilizing a feature of EDM that all the surfaces of an electrode can remove material.

In this method, a continuously rotating electrode is used to form a tapered shape and the electrode feed motion can be controlled by a computer. Improvement in the circularity of drilled holes and the machining time is expected as results.

\section{RESULTS}

\subsection{Drilling using stepped electrode}

Drilling was carried out using stepped electrodes. The experiments in this section employed electrodes of $12 \mu \mathrm{m}$ bent-part diameter and $30 \mu \mathrm{m}$ straight-part diameter, and a $50 \mu \mathrm{m}$-thick plate as the workpiece. The open-circuit voltage was $60 \mathrm{~V}$ with the electrode rotation. It was raised to $100 \mathrm{~V}$ without the rotation in order to increase electrical discharge energy because drilling is slower than with the rotation. Figure 3 shows a stepped electrode, which is $45^{\circ}$ in bending angle $(\theta)$ and $145 \mu \mathrm{m}$ in bent-part length $(L)$.

\subsubsection{Reverse-tapered microhole}

The reverse-tapered microhole shown in Fig. 4 was drilled using an electrode with a $\theta$ of $30^{\circ}$ and an $L$ of $110 \mu \mathrm{m} . F_{1}, F_{2}$, and $F_{3}$ were $75 \mu \mathrm{m}, 100 \mu \mathrm{m}$, and $100 \mu \mathrm{m}$, respectively. The hole is $35 \mu \mathrm{m}$ in entrance diameter and $94 \mu \mathrm{m}$ in exit diameter. The hole's circularity improved with approximate values of $2 \mu \mathrm{m}$ in comparison with that obtained in the previous study ${ }^{5}$ because the reverse-tapered shape was fabricated using a continuously rotating electrode. The machining time was reduced to $3 \mathrm{~min}$

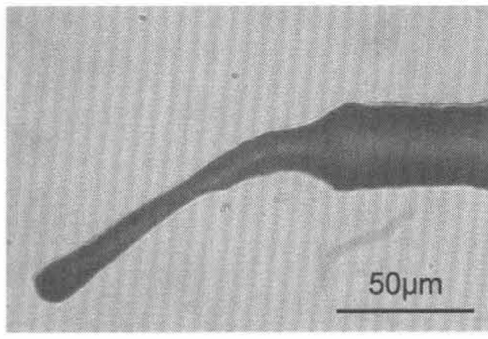

Fig. 5 Electrode after drilling

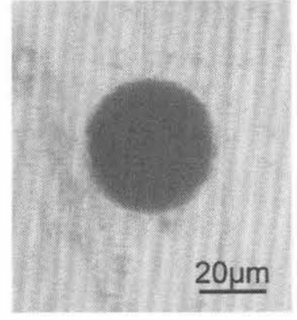

(a) Entrance

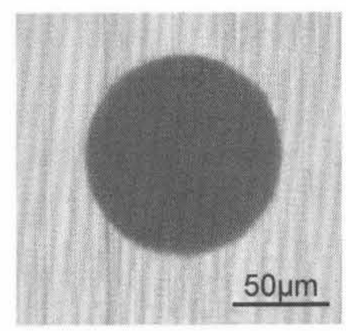

(b) Exit
Fig. 6 Reverse-tapered microhole with indentation removed $\left(\theta=30^{\circ}, L=110 \mu \mathrm{m}, F_{1}=70 \mu \mathrm{m}, F_{2}=\right.$ $100 \mu \mathrm{m}$, and $\left.F_{3}=110 \mu \mathrm{m}\right)$

from $15 \mathrm{~min}$, which had been required for drilling such a hole using the previous approach ${ }^{5)}$.

However, both the entrance and exit have a noticeable indentation on their edges, which were probably formed in the drilling step shown in Fig. 2(b). One reason for this is that the open-circuit voltage in Fig. 2(b) was higher than that in Fig. 2(d), making the discharge gap wider. Another reason is that, as indicated in Fig. 5, the electrode wore greatly and became thin near its bending point. This is because the material volume removed by that part was larger than that removed by other parts of the electrode. For this reason, the hole's diameter was smaller, especially at its entrance, than expected, leaving an indentation there.

To remove such indentations on hole openings, drilling was performed with $F_{3}$ larger than $F_{2}$. Figure 6 shows a hole drilled using an electrode with a $\theta$ of $30^{\circ}$ and an $L$ of $110 \mu \mathrm{m}$. Here, $F_{1}, F_{2}$, and $F_{3}$ were $70 \mu \mathrm{m}, 100 \mu \mathrm{m}$, and $110 \mu \mathrm{m}$, respectively. The hole is $38 \mu \mathrm{m}$ in entrance diameter and $102 \mu \mathrm{m}$ in exit diameter. No indentation is seen on the openings.

The cross sections of holes are shown in Fig. 7. Figures 7(a), (b), and (c) show those drilled using an electrode with $\theta$ values of $15^{\circ}, 30^{\circ}$ and $45^{\circ}$, respectively, indicating that the cone angles of all the holes are approximately twice $\theta$. These results demonstrate that it is possible to fabricate a reversetapered hole with a diameter of less than $100 \mu \mathrm{m}$ and a cone angle of up to $90^{\circ}$.

3.1.2. Combination of straight and reversetapered microholes

Part of a tapered hole must be straight in some applications. Drilling a combination of straight and 


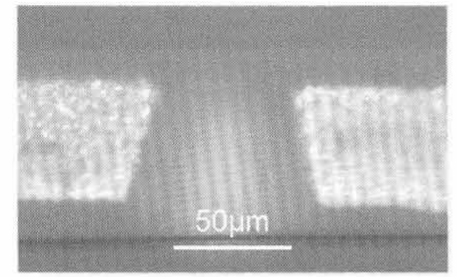

(a) $\theta=15^{\circ}\left(L=165 \mu \mathrm{m}, F_{1}=100 \mu \mathrm{m}, F_{2}=125 \mu \mathrm{m}\right.$, and $\left.F_{3}=145 \mu \mathrm{m}\right)$

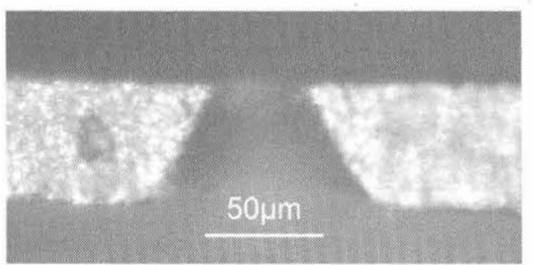

(b) $\theta=30^{\circ}\left(L=110 \mu \mathrm{m}, F_{1}=70 \mu \mathrm{m}, F_{2}=115 \mu \mathrm{m}\right.$, and $\left.F_{3}=120 \mu \mathrm{m}\right)$

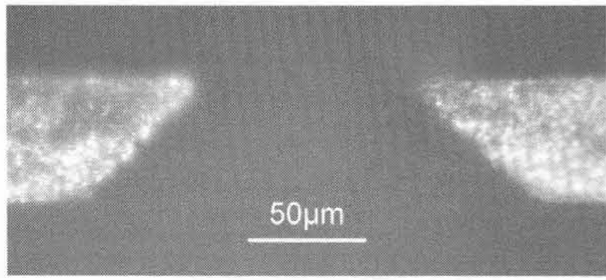

(c) $\quad \theta=45^{\circ}\left(L=150 \mu \mathrm{m}, F_{1}=100 \mu \mathrm{m}, F_{2}=95 \mu \mathrm{m}\right.$, and $\left.F_{3}=135 \mu \mathrm{m}\right)$

Fig. 7 Cross sections

reverse-tapered holes was therefore attempted. The drilling steps are shown in Fig. 8. Such a hole can be drilled by feeding the electrode deeper than when a simple reverse-tapered hole is drilled (Fig. 8(a)). Its straight part is fabricated in the next step (Fig. 8(b)). The electrode is then fed upward such that the straight part is not totally removed (Fig. 8(c)).

Figure 9 shows a combination drilled using an electrode with a $\theta$ of $43^{\circ}$ and an $L$ of $150 \mu \mathrm{m} . F_{1}, F_{2}$, and $F_{3}$ were $110 \mu \mathrm{m}, 78 \mu \mathrm{m}$, and $78 \mu \mathrm{m}$, respectively.

\subsection{Drilling using notched electrode}

Drilling a hole with a smaller diameter than the above ones is difficult to carry out using a stepped electrode, because of the large diameter of its straight part. Bending an electrode, however, requires a diameter change at its bending point. A new type of electrode was therefore fabricated and used, which was notched at its bending point by EDM. Figure 10 shows an electrode bent at its notch, which is $12 \mu \mathrm{m}$ in diameter, $30^{\circ}$ in $\theta$, and $110 \mu \mathrm{m}$ in $L$. A smaller-diameter hole can be expected using such an electrode because of its thinner straight part.

\subsubsection{Reverse-tapered microhole}

Figure 11 shows a reverse-tapered microhole drilled in a $50 \mu \mathrm{m}$-thick plate using an electrode $12 \mu \mathrm{m}$ in diameter, $30^{\circ}$ in $\theta$, and $115 \mu \mathrm{m}$ in $L . F_{1}, F_{2}$, and $F_{3}$ were $90 \mu \mathrm{m}, 75 \mu \mathrm{m}$, and $95 \mu \mathrm{m}$, respectively. (a)

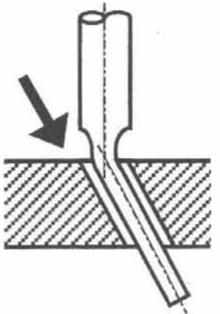

(b)

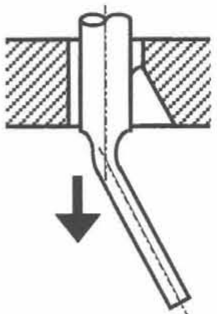

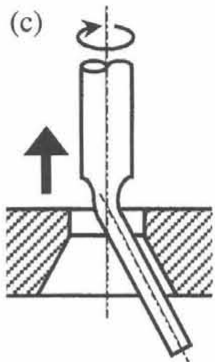

(c)

Fig. 8 Steps in drilling combination of straight and reverse-tapered holes

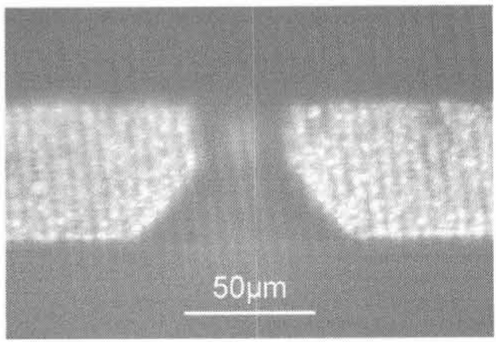

Fig. 9 Combination of straight and reverse-tapered microholes $\left(\theta=43^{\circ}, L=150 \mu \mathrm{m}, F_{1}=110 \mu \mathrm{m}, F_{2}\right.$ $=78 \mu \mathrm{m}$, and $\left.F_{3}=78 \mu \mathrm{m}\right)$

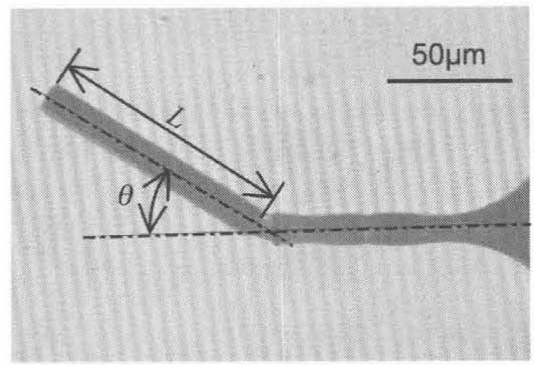

Fig. 10 Notched electrode $\left(\right.$ diameter $=12 \mu \mathrm{m}, \theta=30^{\circ}$, and $L=110 \mu \mathrm{m}$ )

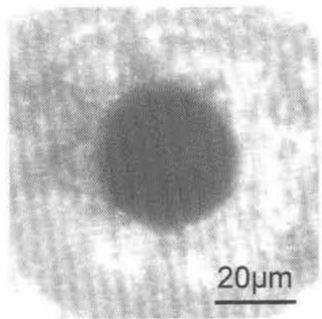

(a) Entrance

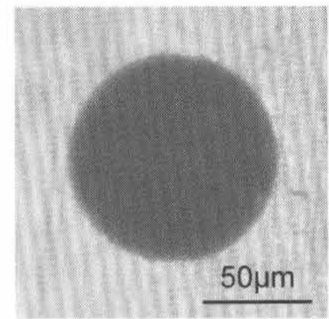

(b) Exit
Fig. 11 Reverse-tapered microhole (workpiece thickness $=50 \mu \mathrm{m}$, electrode diameter $=12 \mu \mathrm{m}, \theta=30^{\circ}, L=$ $115 \mu \mathrm{m}, F_{I}=90 \mu \mathrm{m}, F_{2}=75 \mu \mathrm{m}$, and $\left.F_{3}=95 \mu \mathrm{m}\right)$

The open-circuit voltages were $60 \mathrm{~V}$ with the electrode rotation and $100 \mathrm{~V}$ without the rotation. The hole is $34 \mu \mathrm{m}$ in entrance diameter and $94 \mu \mathrm{m}$ in exit diameter, indicating that the cone angle is $60^{\circ}$. Holes drilled in a $20 \mu \mathrm{m}$-thick plate using a $6 \mu \mathrm{m}$ diameter electrode are shown in Fig. 12. $\theta, L, F_{1}, F_{2}$, 


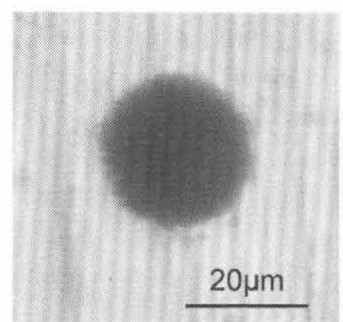

(a) Entrance

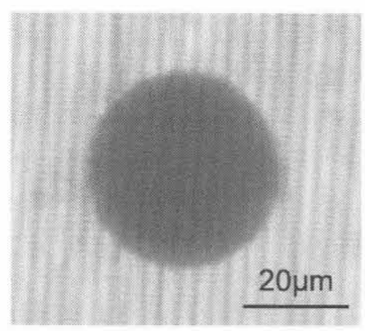

(b) Exit

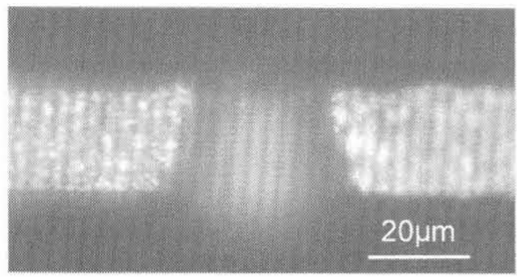

(c) Cross section

Fig. 12 Reverse-tapered microholes (workpiece thickness $=20 \mu \mathrm{m}$, electrode diameter $=6 \mu \mathrm{m}, \theta=15^{\circ}, L=$ $50 \mu \mathrm{m}, F_{1}=40 \mu \mathrm{m}, F_{2}=35 \mu \mathrm{m}$, and $F_{3}=55 \mu \mathrm{m}$ ) (a)

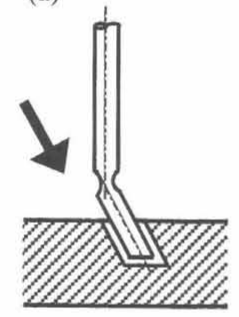

(b)

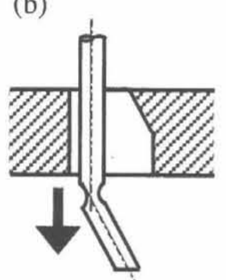

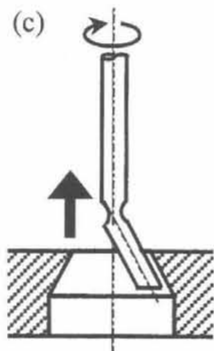

Fig. 13 Steps in drilling combination of reverse-tapered and straight holes

and $F_{3}$ were $15^{\circ}, 50 \mu \mathrm{m}, 40 \mu \mathrm{m}, 35 \mu \mathrm{m}$, and $55 \mu \mathrm{m}$, respectively. The open-circuit voltages were $40 \mathrm{~V}$ with the electrode rotation and $50 \mathrm{~V}$ without the rotation. The hole shown in Figs. 12(a) and (b) is $24 \mu \mathrm{m}$ in entrance diameter and $34 \mu \mathrm{m}$ in exit diameter, being the smallest reverse-tapered hole drilled in the present study. Figure 12(c) shows the cross section of another hole, indicating that its cone angle is approximately $30^{\circ}$.

3.2.2. Combination of reverse-tapered and straight microholes

A combination of reverse-tapered and straight holes was drilled using a notched electrode. This type of hole is difficult to drill using a lathe-type machine ${ }^{2 / 3)}$. The drilling steps are shown in Fig. 13. The electrode does not penetrate through the workpiece in the first step (Fig. 13(a)). After its straight part comes out of the hole's exit (Fig. 13(b)), the electrode is rotated and fed upward until its tip reaches the border between the tapered and straight parts of the hole

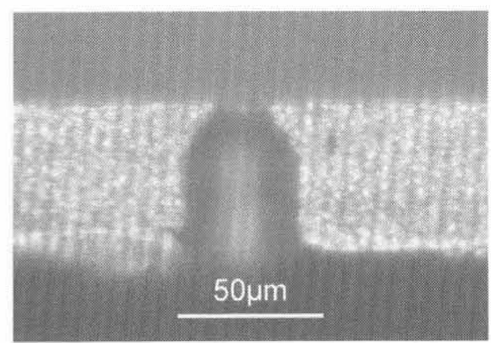

Fig. 14 Combination of reverse-tapered and straight microholes (workpiece thickness $=50 \mu \mathrm{m}$, electrode diameter $=12 \mu \mathrm{m}, \theta=30^{\circ}, L=29 \mu \mathrm{m}, F_{1}$ $=20 \mu \mathrm{m}, F_{2}=70 \mu \mathrm{m}$, and $F_{3}=70 \mu \mathrm{m}$ )

(Fig. 13(c)). The electrode's bent part must be short for this drilling; however, it is not easy to bend an electrode with a short bent part. Therefore, a bent electrode with a long bent part was fabricated and then that part was shortened by WEDG.

Figure 14 shows a combination drilled in a $50 \mu \mathrm{m}$ thick plate using a $12 \mu \mathrm{m}$-diameter electrode with a $\theta$ of $30^{\circ}$ and an $L$ of $29 \mu \mathrm{m} . F_{1}, F_{2}$, and $F_{3}$ were $20 \mu \mathrm{m}$, $70 \mu \mathrm{m}$, and $70 \mu \mathrm{m}$, respectively. The open-circuit voltages were $60 \mathrm{~V}$ with the electrode rotation and $100 \mathrm{~V}$ without the rotation.

\subsection{Chamfering}

The present drilling technique can also be used to chamfer a microhole. It is possible to chamfer one opening of a hole from the opposite opening. Such chamfering is applicable to, for example, the internal deburring of the edges of intersecting holes, which is a difficult task when the holes' diameters are small.

The chamfering steps are illustrated in Fig. 15. A notched bent electrode is inserted through a hole to be chamfered (Fig. 15(a)) and the axis of the electrode's straight part is made to coincide with that of the hole (Fig. 15(b)). The electrode is then rotated and fed upward with the EDM power source being turned on, thus chamfering the hole's lower opening (Fig. 15(c)). Finally, the electrode is extracted (Fig. 15(d)).

Figure 16 shows a $60 \mu \mathrm{m}$-diameter hole chamfered using a $12 \mu \mathrm{m}$-diameter electrode with a $\theta$ of $45^{\circ}$ and an $L$ of $65 \mu \mathrm{m}$. The open-circuit voltage was $50 \mathrm{~V}$. The hole's opening was chamfered to a depth of $10 \mu \mathrm{m}$.
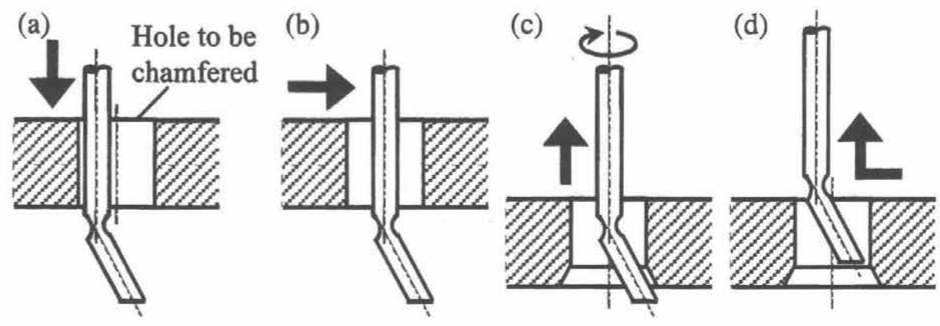

Fig. 15 Chamfering steps 


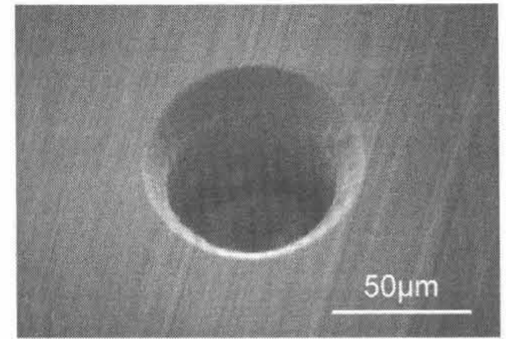

Fig. 16 Chamfered hole (hole diameter $=60 \mu \mathrm{m}$, chamfer depth $=10 \mu \mathrm{m}$, electrode diameter $=12 \mu \mathrm{m}, \theta=$ $45^{\circ}$, and $L=65 \mu \mathrm{m}$ )

\section{CONCLUSIONS}

EDM of reverse-tapered microholes has been performed using bent electrodes. The bent electrodes were fabricated from a stepped or notched straight electrode, which was bent at its step or notch. Using such electrodes, reverse-tapered shapes were obtained by controlling the electrode feed direction and rotation. The following results were achieved.

(1) Reverse-tapered holes with a diameter of less than $100 \mu \mathrm{m}$ and a cone angle of up to $90^{\circ}$ were successfully drilled. The smallest-diameter hole was $24 \mu \mathrm{m}$ in entrance diameter and $34 \mu \mathrm{m}$ in exit diameter.

(2) The circularity of drilled holes and the machining time improved in comparison with those in a previous study.
(3) It was possible to drill combinations of reversetapered and straight microholes, and straight and reverse-tapered microholes.

(4) This technique was applicable to the chamfering of one opening of a hole from the opposite opening.

\section{REFERENCES}

1) A. Goto, K. Watanabe and A. Takeuchi: Method to machine a curved tunnel with EDM, International Journal of Electrical Machining No.7 (2002) pp.43-46

2) T. Masuzawa, K. Okajima and M. Fujino: EDM-lathe for micromachining, Annals of the CIRP, Vol.51, No.1 (2002) pp.355-358

3) A. Uchimura, T. Masuzawa and M. Fujino: Development of micro-EDM lathe -influence of taper angle on processing characteristics-, Proceedings of the Annual Spring Meeting of the Japan Society for Precision Engineering, (2006) pp.681-682 (in Japanese)

4) C. Diver, J. Atkinson, H. J. Helml and L. Li: MicroEDM drilling of tapered holes for industrial applications, Journal of Materials Processing Technology, Vol.149, No.1-3, (2004) pp.296-303

5) K. Egashira, H. Tsuchiya and M. Miyazaki: EDM of reverse-tapered microholes, Proceedings of the 3rd International Conference on Leading Edge Manufacturing in 21st Century (LEM 21), (2005) pp. $757-760$

6) T. Masuzawa, M. Fujino and M. Kobayashi: Wire electrodischarge grinding for micromachining, Annals of the CIRP, Vol.34, No.1 (1985) pp.431-434 